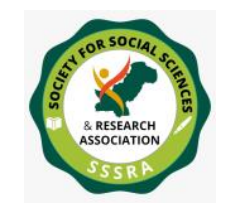

\title{
THE PERSPECTIVE OF THE RESIDENTS OF SOHARB GOTH ABOUT THE AFGHAN REFUGEES IN THEIR COMMUNITY
}

\author{
Fauzia Darabu \\ Ph. D Scholar \\ Department of Humanities and Social Sciences \\ Greenwich University \\ Karachi-Pakistan \\ fauziadarabu@gmail.com \\ Prof. Dr. Shahida Sajjad \\ Vice Chancellor \\ Metropolitan University \\ Karachi - Pakistan \\ shahida_sajjad75270@yahoo.com
}

\begin{abstract}
The purpose of this study was to analyze the impact casted on local residents of Sohrab Goth, Karachi during 1990-2015, due to the massive migration of Afghans to this area. A Mixed Research was carried out to observe changes in the social trends of the people living there before 1990 and after the arrival of Afghan refugees till 2015. As this report was based upon the opinions of the residents of Sohrab Goth, therefore Frequency Distribution along with Bar-Chart was used to indicate the general perception of the respondents. Sampling size was kept 30 selected by convenience method. Interviews were conducted from local residents of Sohrab Goth. The survey included the old Pashtuns men and women living in Sohrab Goth for years. Besides, young Pashtuns working in posh areas of Karachi as sales man in different shopping malls were also included as respondents. SPSS software was used for data analysis to find out the outcome of the problem. Results and findings rejected the hypotheses. The findings also pointed out that only Afghan refugees cannot be held responsible for the bad law and order situation in that area. Besides, in order to uproot the factors invigorating the negative impact on the life of the local residents of Sohrab Goth, some bold steps have to be taken by the
\end{abstract}




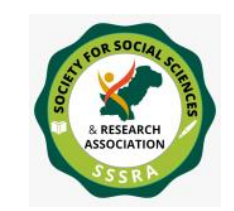

Pak. Journal of Int'L Affairs, Vol 4, Issue 4 (2021) The Perspective of the Residents of Soharb ...

Government of Sind along with a permanent solution for these Afghan refugees to live in Karachi without fear and despair till they go back to their own country.

KEYWORDS: Migration, Refugees, Impact, Law And Order Situation, Inflation

\section{Introduction}

A massive wave of migration engulfed Pakistan when the then Soviet Union in 1979 invaded Afghanistan. Pakistan extended a helping hand to Afghans who were compelled to flee their own country and take refuge in Pakistan. Many of these Afghans came to Karachi and started to settle in various areas. It was very difficult for the Afghan refugees to find a place for themselves in the beginning. The presence of Akakhels and Deo-Band groups of Pashtuns, since 1970s in Sohrab Goth, paved the way for the Afghan refugees to get settled in this metropolitan city. Since then, the Afghan refugees have spread to every nook and corner of Karachi. Thus this scenario made it somewhat difficult not only for the local residents where they were living, but for the Sindh Government also while addressing the problems well connected to such situations. Keeping in view this problem, this research will try to explore the impact of the migration of Afghans especially to this area and on the life of the local residents of Sohrab Goth. An effort will also be made to find out the problems occurred after this migration. Besides, with the help of interviews from the local residents an effort will also be carried out to find out that whether the root cause of some of the common social problems like, inflation, increased rate in crime and law and order situation of Sohrab Goth has connection with the migration of Afghan refugees. This research will make an attempt to observe the overall impact of this migration on the social life of Karachi city in general. This research will also explore the changing social trends of Sohrab Goth especially after 1980s. This research will enable to bring forward the actual facts behind the bad social condition of the local residents of Sohrab Goth. Besides, an effort will be carried out to find out the magnitude of the problems created on the life of a common man by the Afghan refugees to this area. Similarly some recommendations will be put forward that may help to curtail the anti-social elements of this area, occurring due to this migration.

This research study will make an attempt to formulate the reasons behind the difficult social scenario of the residents of Sohrab Goth. This research is being carried out to compare the social setup of Sohrab Goth before the arrival of Afghan refugees and after 1980.Keeping a sample size of 30, interviews will be conducted to find the factors responsible for the social degradation of this area. This research will be based on interviews with the local residents of Sohrab Goth, which may help to find out the 
The Perspective of the Residents of Soharb ...

magnitude of the problems as well as may come up with some suggestions to overcome the problems faced by the local residents after the arrival of Afghans in the area.

\section{Objectives}

1) To find out any influence of migration of Afghans on socio-cultural aspect in Sohrab Goth, in Karachi, in terms of wedding, dress, food habits, functions etc.

2) To explore the effects of migration of Afghans on the hygienic condition of the community of Soharb Goth.

3) To investigate the effect of spread of drugs in the area especially after 1990.

4) To find out the impact of weapons on the residents of Sohrab Goth.

5) To find the impact between the Afghan refugees and the increasing crime rate in Sohrab Goth, Karachi.

\section{Research Questions:}

Q1.How migration of Afghan refugees has been affecting the socio-culture aspect of Karachi, especially of Sohrab Goth?

Q2.To which extent the migration of Afghanis has affected the hygienic condition of the local residents in Sohrab Goth.?

Q3.What kind of adverse effect is created by the drugs on the social set up of Sohrab Goth in Karachi?

Q4. What kind of impact has created by the spread of weapons on the society of Sohrab Goth?

Q5. What is the link between the migration of Afghans to Karachi and the increasing crime in Sohrab Goth?

\section{Hypothesis}

The hypothesis of this research is,

H1=The Afghan refugees have no effect on the social life of Sohrab Goth.

$\mathrm{H} 0=$ There is a great impact of migration of Afghans on the social life of Sohrab Goth.

\section{Definition of Terms:}

\section{Migration:}

According to Oxford Dictionary (online), the term migration is defined as; "A movement of people to a new place or a country in order to find work or better living conditions." 
The Perspective of the Residents of Soharb ...

In this research study, migration of Afghans to Pakistan, especially after the Soviet invasion in Afghanistan has been discussed.

\section{Refugees:}

Merriam-Webster Dictionary (online) defines an refugees as,

"Any person who takes up permanent residence in a country."

This research study has focused the Afghanis as refugees to Pakistan after 1989 onwards. Their impact especially to Sohrab Goth, a town of Karachi city has been taken into account.

Amenities: Dictionary (online) defines amenities as;

Things of daily use like food, water, shelter, comfort, convenience, or pleasure to people. This research study has discussed the problems the local residents faced because of the arrival of Afghan refugees to the locality of Sohrab Goth.

- Local Residents: People living in a particular area are called its local residents. In this research report the people residing in Sohrab Goth are being discussed as the local residents.

\section{Research Methodology}

This research is an exploratory research study. Case-Study research study will be used as there is a single population of a specific area of Karachi that is Sohrab Goth. The sample size will be of 50 local residents of Sohrab Goth. Data collection will be based on interviews of the local residents of the area. Analysis will be done by using SPSS, as we have to find the effect of the arrivals of Afghans refugees on the society of Sohrab Goth.

\section{Duration Required}


The Perspective of the Residents of Soharb ...

The duration is distributed as follows:

\begin{tabular}{|l|l|}
\hline Task & Time period \\
\hline Literature Review & 08 days \\
\hline Interview(formulating questions etc) & 04 days \\
\hline Data Collection & 12 days \\
\hline Data editing & 05 days \\
\hline Data coding \& entry & 07 days \\
\hline Entry of data & 04 days \\
\hline Data Analysis & 08 days \\
\hline Report writing & 12 days \\
\hline Total days & 60 days (approximately) \\
\hline
\end{tabular}

\section{LITERATURE REVIEW}

\section{Definition and Origin of Migration}

The term migration has been defined by Merriam Webster Dictionary as to "move from one country or place to live or work." On the other hand, United Nations Education and Scientific and Cultural Organization (UNESCO) has explained migration as a process by which any man or a woman lives in a country for both for a short period defines human migration as "a movement of people from one place in the world to another for the purpose of taking up permanent or semi -permanent residence, usually across a political or a permanent period where he/ she is not born .Several authors consider migration as a step in the evolution of mankind, the reason being that its history dates back to approximately ninety thousand years (Sullivan, 2010). The source of its origin is Africa from where people ventured out to different parts of the world for may be better living, food or better environment.

\section{Types of Migration}

According to the National Geographic, (2005) migration may be categorized as:

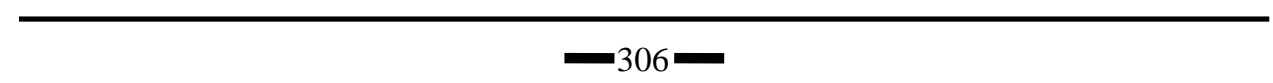




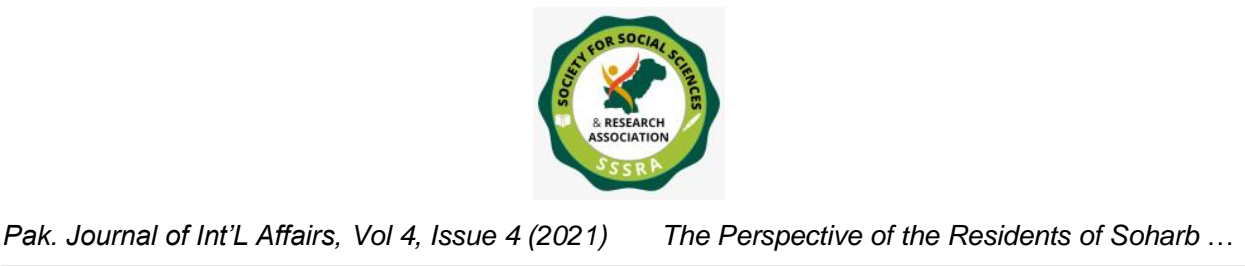

- Internal Migration: When a person finds a new home within the same state, for example moving from New Jersey to California.

- External Migration: When a person finds a home in a different country. For example going to United Kingdom from Pakistan.

- Emigration: To leave one country to move to another for the purpose of pilgrim for example going to Saudi Arabia from Pakistan to perform Umra or Hajj.

- Immigration: To move to a new country and live there on permanent basis. For example many Pakistanis have acquired US citizenship within last fifteen years.

- Impelled Migration: It is also termed as imposed or reluctant migration as sometimes people are compelled to move to a new country due to situation not favorable to them and their family. The best example of this is of Afghan People who are forces to take shelter in Pakistan, Iran and other counter countries after the Russian invasion of 1979.

- Step Migration: When people move to other places in steps like first they may move to a village from a farm then to a town then to city and then they move to a new country if they want to. The early human migration is one such example of step migration.

- Chain Migration. When a person moves out to a new country and calls his or her family member one by one to that country, then this is termed as a chain migration.

- Migration Stream: When people migrate to a new city, region or a country in a group, it is termed as Migration Stream. The term is also being defined as a pattern of migration followed by any racial group from one place to another in search of better jobs or better living conditions.

\section{Reasons for Migration}

Since migration of human beings has been an ongoing process therefore, there have been a number of factors and reasons which had in the past and at present invigorated this process. Following are some of the reasons which have become the base of migration for people across the globe. 


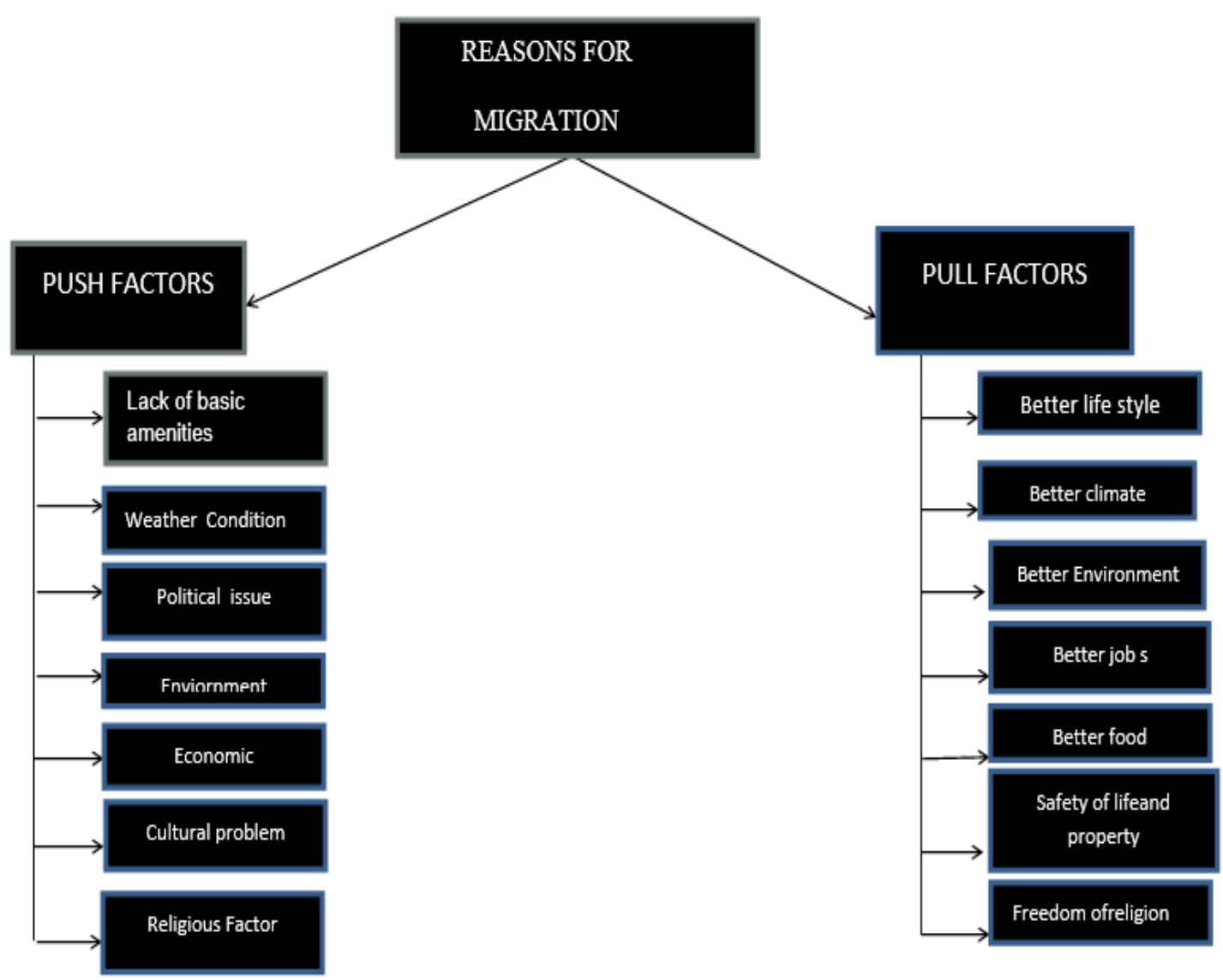

Therefore, for one or the other reasons mentioned above, the people have been on the hunt to find things better for them in order to live a peaceful and prosperous life.

\section{Impact of Migration on the Host and the Source Country}

According to Hollifield (2012), migration has been a part of human history and has been towards high side since WWII. It has also been reported that the twenty first century opened up the gates for migration and as many as two hundred million people are living outside their own homeland. It is a fact that country which receives refugees often gets a number of things which benefit the country, that include workers both skilled and unskilled. "On the other hand the source country gets remittance sent by the refugees, which no doubt adds to its economy." (Hollifield, 2005) On the contrary Wenier, (1995) 


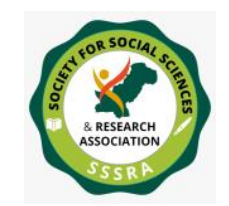

Pak. Journal of Int'L Affairs, Vol 4, Issue 4 (2021)

The Perspective of the Residents of Soharb ...

observes that there has been a great wave of migration in the post war periods, which increased the rate of migration across the globe. This invigorated instability, insecurity, besides disturbing the peace of the world. Migration also becomes a source of diffusion( National Geographic, 2005).It says that during migration certain characteristics like personal ideas, culture, customs etc. also move through people who migrates. Sometimes the ideas moves with people and it does not remain with the point of origin. Sometimes the cultural trait also moves with the ideas but it is not lost. It also may happen that migration brings change in the structure of buildings or styles, reflecting the culture who occupies them.

The nations themselves are responsible for the speedy migration. It has been argued that, "The states must show some responsible attitude to control the pouring in and out of refugees or refugees" (Freeman, 1998, Guiraudon \& Lahav, 2000; Hollifield, 2005). The reason being that high rate of migration can create such impact which may be felt not only by the economy of the host country but also by its local residents. The burden of refugees and refugees can impose a harmful and an invisible damaging effect on the host country. The Brookings Institute has observed that during the period of 1980-2000, the effect of depression in wages on the host country was about $2.3 \%$.While the Center for Immigration Studies has calculated a depression of about 3.7\% in wages during 1980-2000. These refugees usually try to compete with the local residents for their place in their community for their needs, including, education, food, water supply, transportation, jobs etc. (United Nations High Commissioner for Refugees, 2004). Besides, there is a very strong impact on the cost of living in the countries which host refugees. It has also been observed that demand of items of daily use also increases especially near the areas where the refugees live thus, indirectly increasing the rate of inflation across the country (Whitaker, 2002). Sometimes these refugees contribute a lot for the society if they are well educated. We can take example from countries like Amman and Jordan in this regard, where the Iraqi educated refugees uplifted the standard of the local hospitals, universities and business (Crisp et al, 2009). Socially, these refugees may become a source of creating tension in the areas where they live. For this we can take the example of Kosovo-Albanian refugees in Macedonia, where the ethnic tension was created between Serbs and ethnic Albanians (Pini, 2008).

As far as Pakistan is concerned it has been reported that after the Soviet invasion in Afghanistan, around 3.3million Afghan refugees got settled on Pak-Afghan Border. This numbered increased to five million when United States and its allied forces began their operation (Khan, 2016). With time, these Afghan refugees spread across other areas of Pakistan, especially to Karachi city, the trade hub of Pakistan. 


\section{Impact of Migration on Karachi}

Karachi is one of the most populated cities of the world. It lies in the southwest of Pakistan with an area of 3,527 kilometers square. It has the geographical co-ordinates of $24 * 52 * 0$ north $67 * 3$ ' 0 east. Karachi has a big coastline starting from Cape Monze in the west to Gharo in the east. With time, Karachi is losing its native residents who were Sindhi. According to the census of Pakistan of 1998, the ethnic composition of Karachi is as follows:

\begin{tabular}{|l|ll|}
\hline SNo. & \multicolumn{3}{|l|}{ Ethnic Composition of Karachi( Census 1998) } \\
\hline 1 & Urdu & $=49 \%$ \\
\hline 2 & Punjabi & $=14 \%$ \\
\hline 3 & Pushtu & $=11 \%$ \\
\hline 4 & Sindhi & $=07 \%$ \\
\hline 5 & Balochi & $=04 \%$ \\
\hline 6 & Saraiki & $=02 \%$ \\
\hline 7 & Others & $=12 \%$ \\
\hline
\end{tabular}

It is reported that, the city witnessed a great decline in the population of its local residents from $60 \%$ in 1941 to $7 \%$ in 2014.There were three major migration waves which has gradually changed the demography of the city. The first group of refugees was Muslims from India after the independence of 1947. Second wave of refugees came from Bangladesh after the war of 1971 between Pakistan and India. The third and still ongoing migration is from Afghanistan which started in 1979 with the Soviet invasion in Afghanistan. It has been estimated that the population of Karachi is about twenty two million in 2014 (Zia-ur-Rehman, 2014). It has been reported that Karachi has been a hub of about $65 \%$ of industries of Pakistan and $80 \%$ of trade, banking and other finances which made it attractive for the people from all over Pakistan (Husain, 1994). This attraction for a better life might be one of the reasons of making Karachi a metropolitan city. On the other hand, Bengali (2011) is of the opinion that there has to be a check and balance over pouring in of refugees in Karachi from other parts of the country especially Pashtuns 


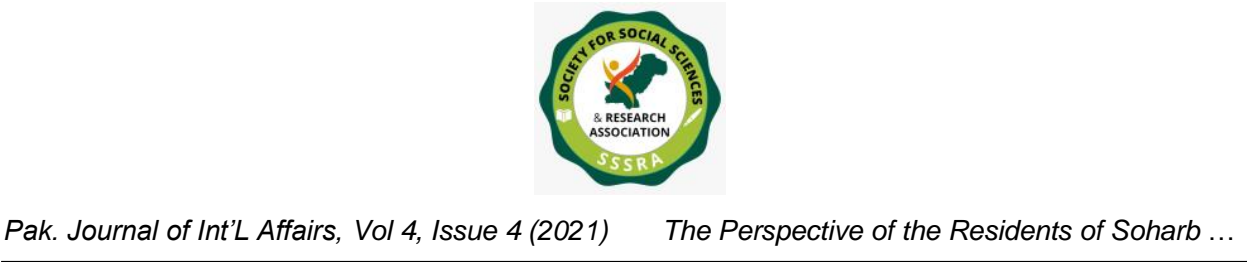

whose number has considerably increased from $3 \%$ in 1941 to $15 \%$ in 2011 . He warns the Sindh government that no further check and balance over the issue would increase this number to $40 \%$ by 2040 .

\section{Location and Demography of Sohrab Goth}

It is a suburb of Gadap Town of Karachi City. Actually it is an illegal 'goth' settlement on encroached land ,built in 1970.Sohrab Goth or Haji Hassan Colony is a gateway to Karachi from all over Pakistan the countries from its northwestern border. A bridge over Lyari River connects Sohrab Goth to the rest of Karachi. Its geographical co-ordinates are $24 * 56$ ' 43 North, and $67 * 5$ ' 12 East. Sohrab Goth has been a paradise for the people of northern parts of Pakistan since long even. The arrival of Afghans in Karachi has an old history. Afghans used to come to Karachi long before 60s and 70s.Most of them were shepherds and semi-nomadic people. (Afghan Refugee Evaluation Unit, 2005). In order to get away from the harsh climatic conditions, the Afghans used to come to Pakistan back when the weather become favorable for them. The Pashtuns who used to come here were mostly from the northern tribal areas of Pakistan. These Pashtuns were either Akakhels or Mehsoods. These were traders bringing smuggled goods here through the northern areas of Pakistan. Majority of these Pashtuns were Akakhels or Koochis (as many of them migrated in this area from Koochi Bazar of Peshawar), later on moved away far from city towards Sohrab Goth and other areas of the city after the Great Massacre of 1986. After the Russian Invasion of 1979, it was reported that most of the Afghan refugees came to Karachi from various districts of Afghanistan which includes, Kunduz, Khan Abad and Chahar Darra. Most of these Afghans are either Pashtuns, Uzbeks and Tajiks (Zia-ur-Rehman,2016).The United Nation High Commissioner for Refugees (UNHCR) has pointed out that around 62,500 Afghan refugees are in Sindh and out of them around $85 \%$ are living in union council-4 and union council-5 of Gadap Town.

\section{Afghan Refugees and the local Residents of Sohrab Goth}

In order to find out the perception of the local residents about the Afghan refugees, the researchers visited two localities of Sohrab Goth that is Haji Namatullah Town and Machar Colony. To make the report more authentic, the researcher interviewed some Pashtuns who work or own shops in the posh locality of Defense and Clifton. It was an interesting experience as the outcome of the interviews was quite contrary as what was heard about this area in general and about Afghans in particular. The local Pashtuns are simple people and most of them had no interest in other affairs. Most Pashtun men work in shopping malls of Defense and Clifton so they leave very early from Sohrab Goth and usually come late. Therefore most of them were not ready to say anything about Afghans. 


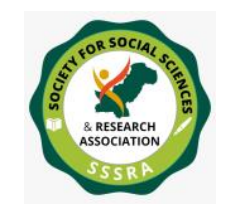

Pak. Journal of Int'L Affairs, Vol 4, Issue 4 (2021) The Perspective of the Residents of Soharb ...

Secondly, it was very surprising that if an elder ly person is speaking, no one else is allowed to say something. Thirdly, the only difference which the researcher has found in order to distinguish between a Pashtun and an Afghani was the dressing of their females. The female Afghani wears 'Shalwar Kameez' whereas a Pashtun female wears typical Pathani frock like shirt. The homes of a Pashtun was more systematically set and clean as compared to an Afghani home.

To find out more about the Afghanis, interviews and a survey was carried out to know the perception of Pashtuns about the Afghans.

\section{Methodology}

This research report was based upon the perception and opinions of the local residents of Sohrab Goth (the Pashtuns) about the impact of Afghan culture due to the presence of Afghan refugees in their community. This research was both Qualitative and Quantitative Research in nature. Population for this research was selected from two areas of Sohrab Goth that is Haji Namuttullah Town and Machar Colony. Due to certain hindrances, a Convenient Sample size of 30 respondents was taken. For the purpose of data collection, structured questionnaire was used as an instrument. As far as the designing of the questionnaire was concerned, no pattern based on the same topic was found, therefore after working on certain questionnaire, an appropriate questionnaire was made with the consent of the supervisor. It was further modified after pilot testing the questionnaire. After visiting the above mentioned areas and meeting personally with the local residents, the questionnaire was made simpler. The questionnaire comprised of some open ended and closed ended questions. SPSS software was used to test the closed ended questions. In order to depict the trend of the respondents towards the questions, Frequency Distribution was applied. It also helped to find out the impact of Afghan refugees on the culture of the local residents of the area.

\section{RESULTS ANALYSIS}

This research is based upon the opinions and perceptions of local residents of Sohrab Goth. Respondents who shared their opinion for this research were Pashtuns residing in Haji Namautullah Town and Masher Colony, Sohrab Goth. Frequency Distribution was used not only to analyze the perception of respondents but to get an overview of the opinions of the respondents. There were total 30 respondents out of which 28 were male and 02 were females. Out of 20 questions, 17 were selected. Three (3) questions were based on personal information about the respondents that is why they were omitted. Findings were supported 
by bar chart with percentile to show the trend of the answers of the local residents of Sohrab Goth.

\section{Frequency Distribution of the Data \\ (Questions 1-17 with Bar Chart)}

\section{Gender of the sample}

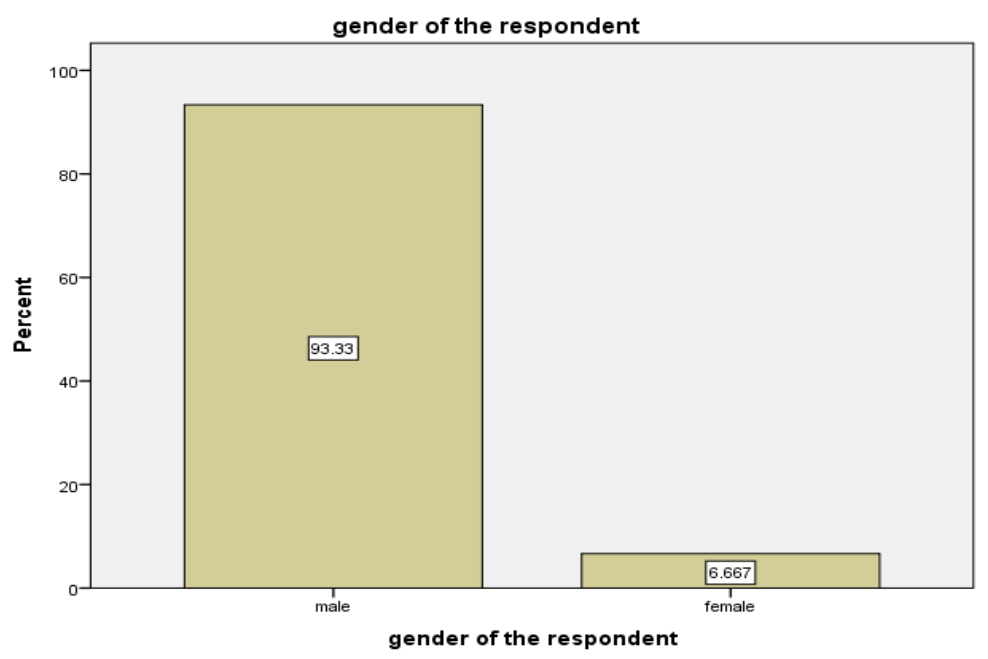

(Fig i)

The above graph shows that there were $93.33 \%$ males and $6.667 \%$ female respondents.

\section{Age of the respondents}


The Perspective of the Residents of Soharb ...

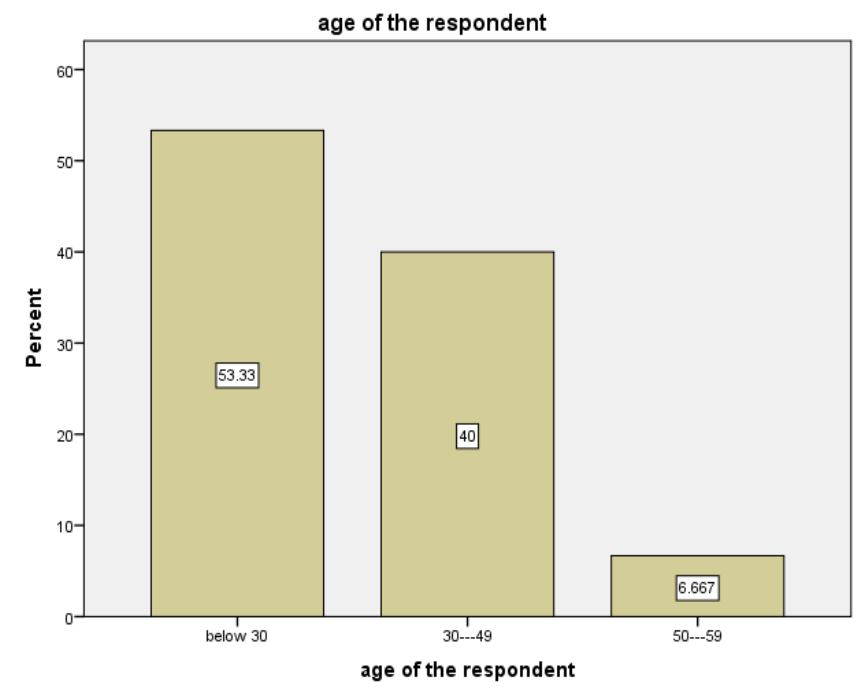

(fig.ii)

The graph indicates that $53.33 \%$ respondents belonged to the age bracket of less than 30 , $40 \%$

were in 30-49 age bracket and $6.667 \%$ respondents fall in the age bracket of 50-59 years.

\section{Academic Qualification of the respondents}

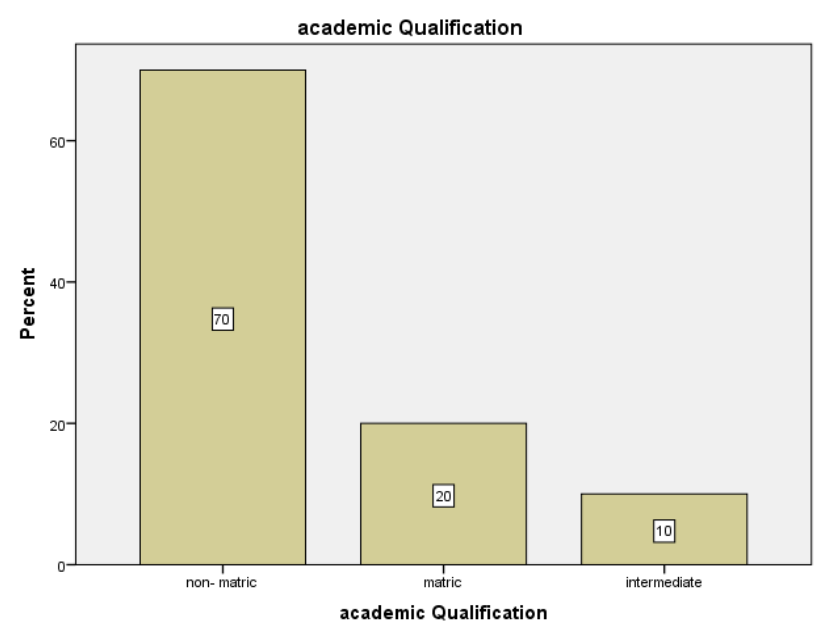

(Fig.iii)

The above graph shows that $70 \%$ of the respondents are not even matriculate, $20 \%$ were matric and $10 \%$ of the respondents were intermediate. 


\section{Time period of the respondents living in the area}

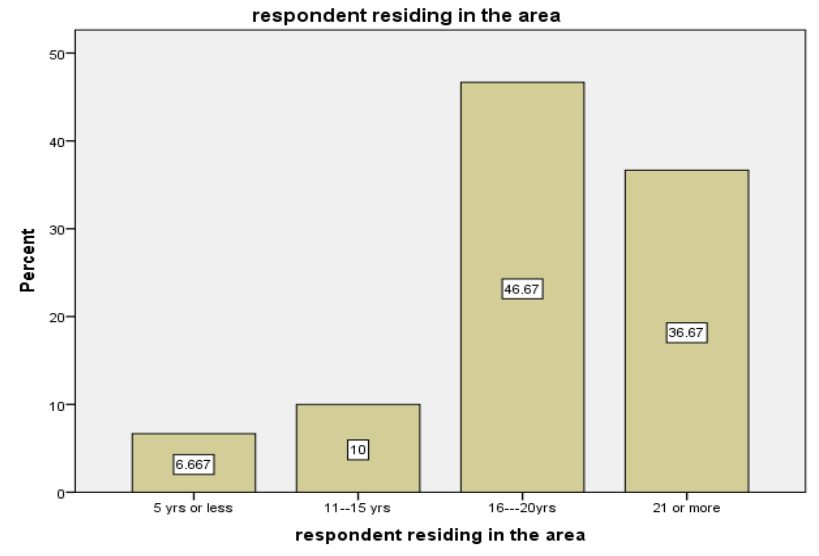

(figiv)

The above graph shows that $36.67 \%$ respondents were living in the areas for the past 21 or more years, $46.67 \%$ were residing there since 16 or more years, $10 \%$ of the reseondents were residing there for the past 5 or less years.

\section{Attitude of Afghans}

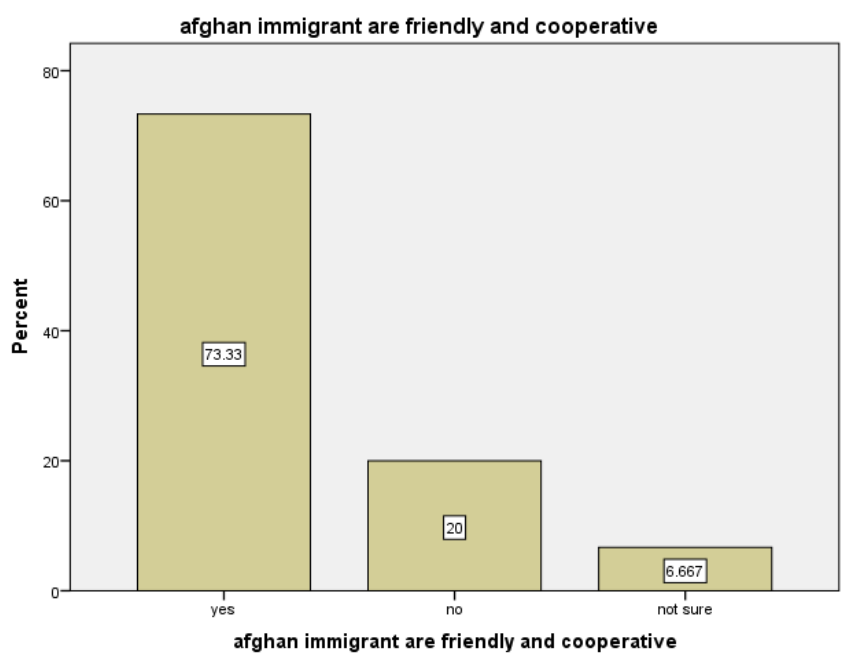

(fig.v)

The graph indicates that $73.33 \%$ of the respondents were of the opinion that the Afghans are friendly and co-operative in nature, $20 \%$ disagreed with the question and $6.667 \%$ were not sure what to say. 


\section{Adopting Afghan food}

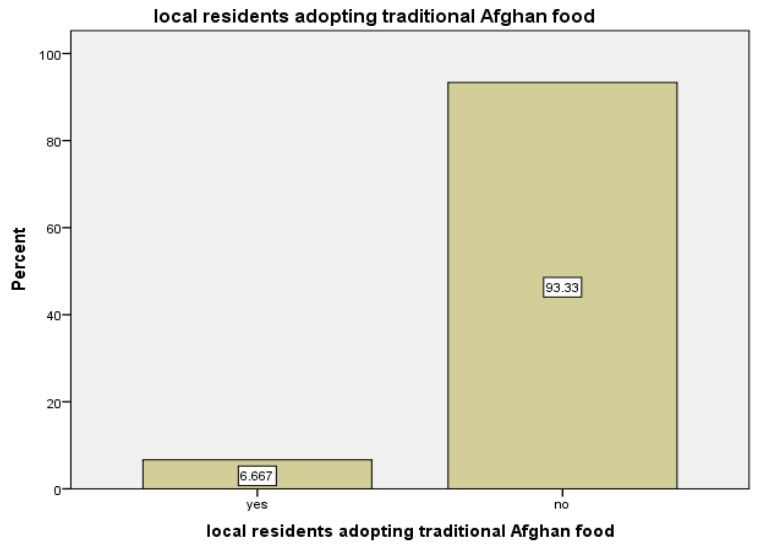

(fig.vi)

The above graph shows that $93.33 \%$ strongly disagreed that they are adopting the Afghan food, $6.667 \%$ agreed with the statement.

\section{Locals adopting Afghan wedding dresses}

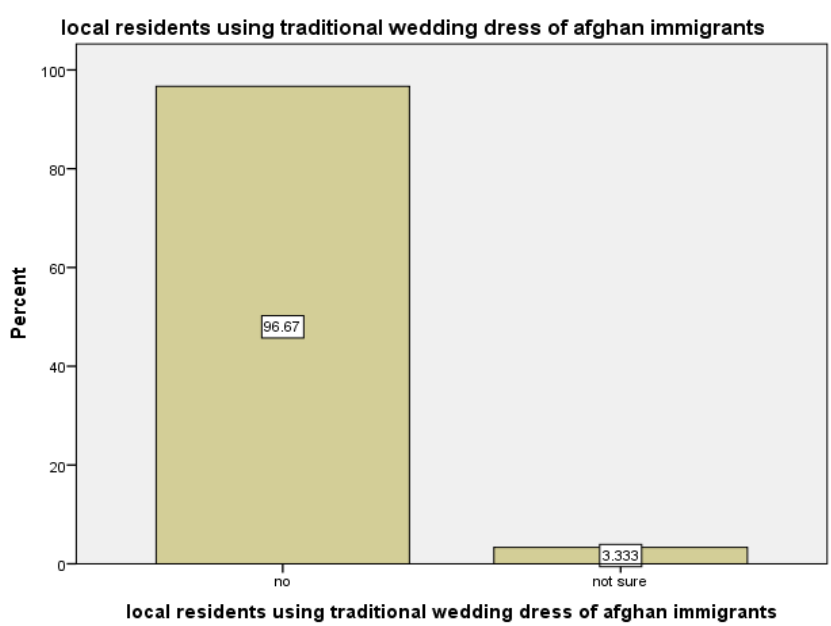

(fig.vii)

The above graph indicates that the $96.67 \%$ local residents disagreed that they were adopting Afghan wedding dresses, while $3.333 \%$ agreed with the statement. 


\section{Locals celebrating occasions like Afghan refugees}

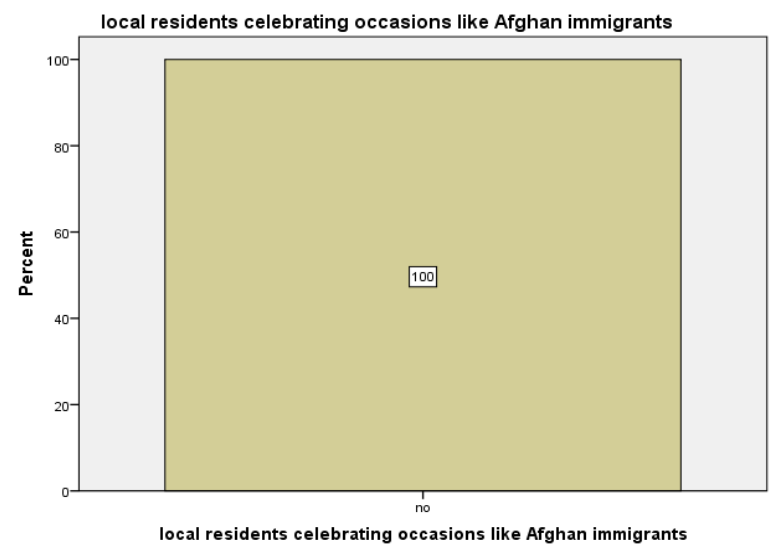

(fig.viii)

The above graph shows that $100 \%$ residents said that they celebrate occasions that like of Afghan refugees.

\section{Locals like to invite Afghan refugees}

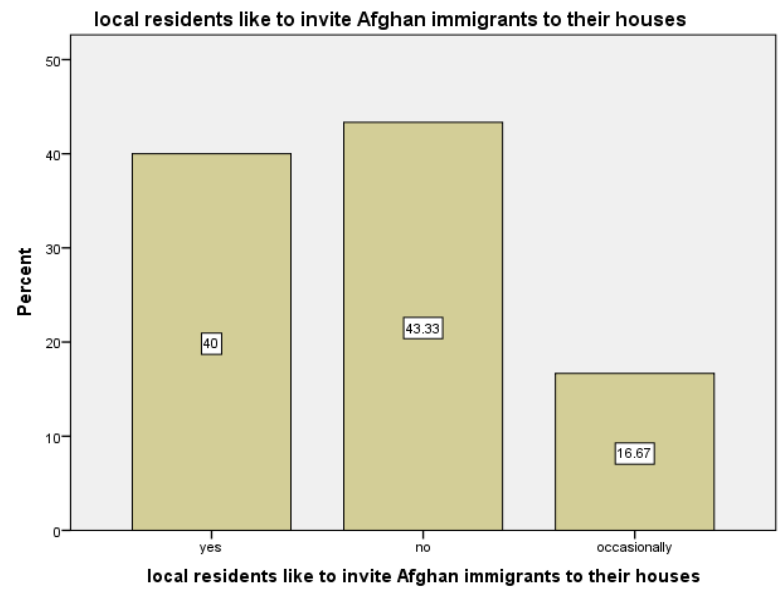

(fig.ix)

The above graph indicates that $40 \%$ locals like to invite the Afghan refugees, $43.33 \%$ do not like to invite them, while $16.67 \%$ like to invite the Afghan refugees occasionally.

\section{Major reason for not inviting Afghan refugees}




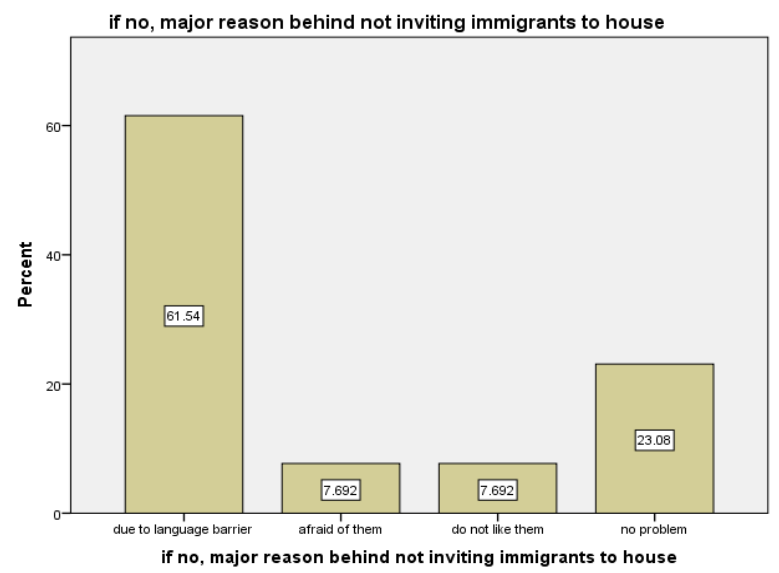

(fig.X)

The above graph indicates that the major reason for not inviting Afghan refugees to their house was language barrier which accounts for $61.54 \%, 7.692 \%$ were of the opinion that they were either afraid of the Afghan refugees or do not like them. $23.08 \%$ were of the opinion that they had no problem with the Afghan refugees.

\section{Locals like to visit the Afghan Refugees}

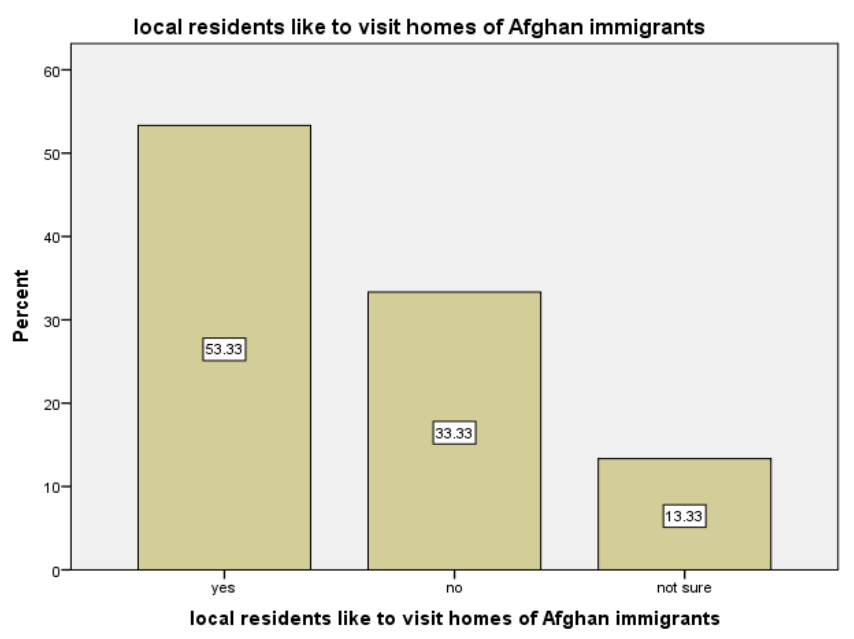

(fig.xi) 
The Perspective of the Residents of Soharb ...

The above graph shows that $53.33 \%$ like to invite Afghan refugees, $33.33 \%$ do not like to invite then while $13.33 \%$ were of the opinion were not sure.

\section{Reasons for not visiting}

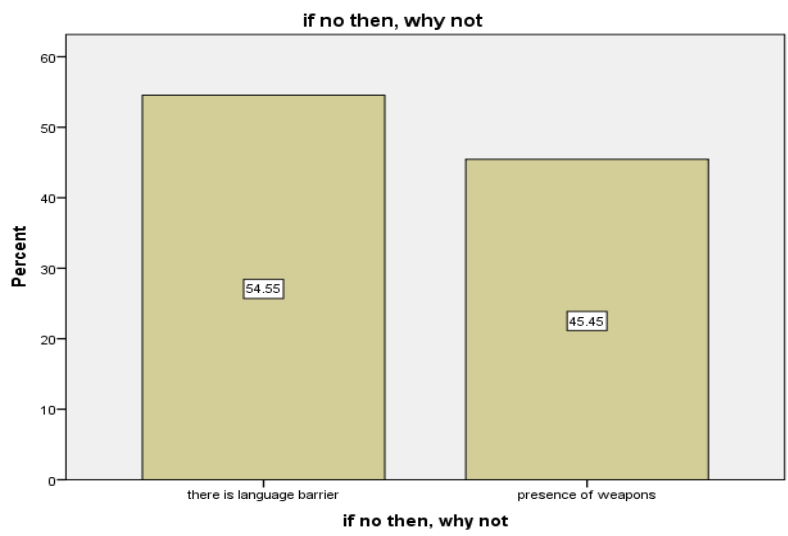

(fig.xii)

The above graph indicates that $54.55 \%$ respondents were of the opinion that due to language barrier they do not invite Afghan refugees while $45.55 \%$ were of the opinion that Afghan refugees have weapons they do not like to invite the Afghan refugees.

\section{Presence of Afghan Refugees}

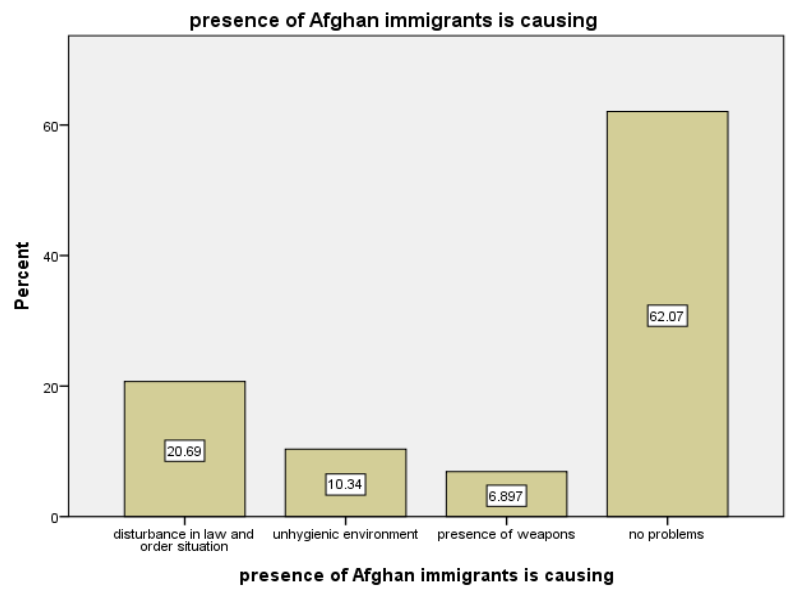

(fig.xiii)

The above graph indicates that $62.07 \%$ locals were of the opinion that they had no problem with the Afghan refugees, 20.69\% were responsible for disturbing in law and order, $10.34 \%$ were of the opinion that Afghan refugees were causing unhygienic condition, 
The Perspective of the Residents of Soharb ...

while $6.897 \%$ were of the respondents blamed the Afghan refugees to spread weapons in the area.

\section{Happy with the presence of Afghan Refugees}

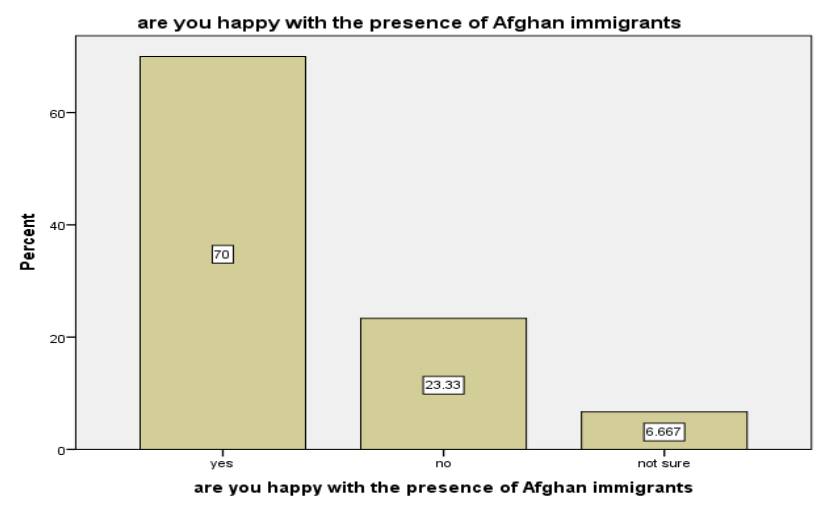

(fig,xiv)

The above graph shows that $70 \%$ of the respondents were happy with Afghan refugees, $23.33 \%$ disagreed with it while $6.667 \%$ were not sure what to say.

\section{Reason for saying Yes}

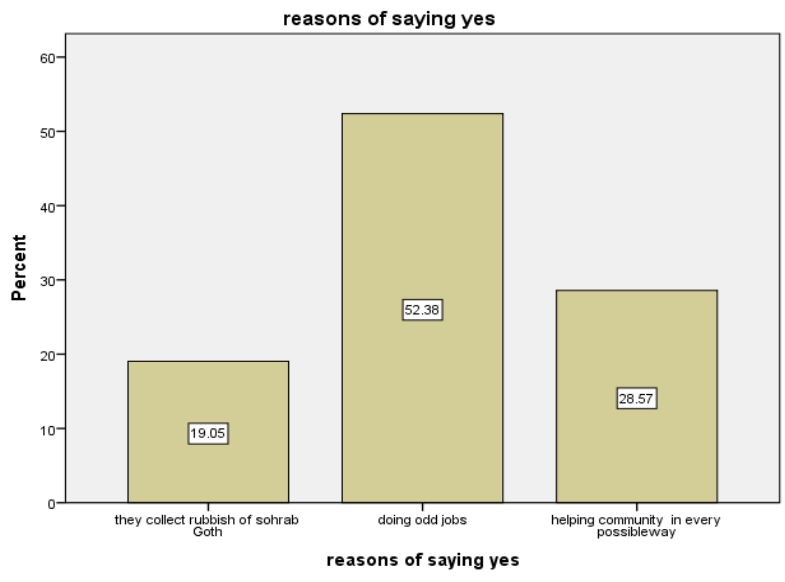

(fig $\mathrm{xv}$ )

The above graph indicates that $52.38 \%$ appreciated the Afghan refugees for doing odd jobs in the area, $28.57 \%$ of the respondents appreciated them for helping out the community in every possible way while $19.05 \%$ appreciated the Afghan immigranst for collecting rubbish from their area. 


\section{Afghan Refugees should go back}

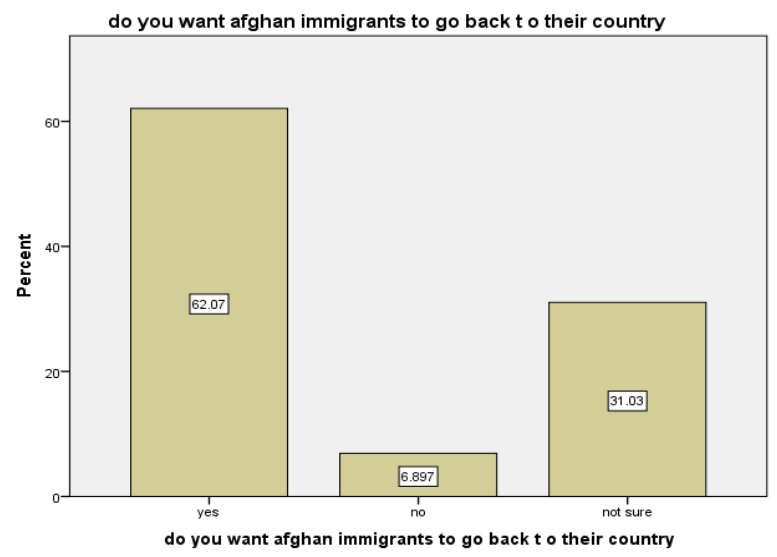

(fig xvi)

The above indicates that $62.07 \%$ respondents wanted the Afghan refugees to return to their country, $31.03 \%$ were not sure about it while $6.897 \%$ wanted the Afghan refugees not to go back to their country.

\section{The prime reason for saying Yes}

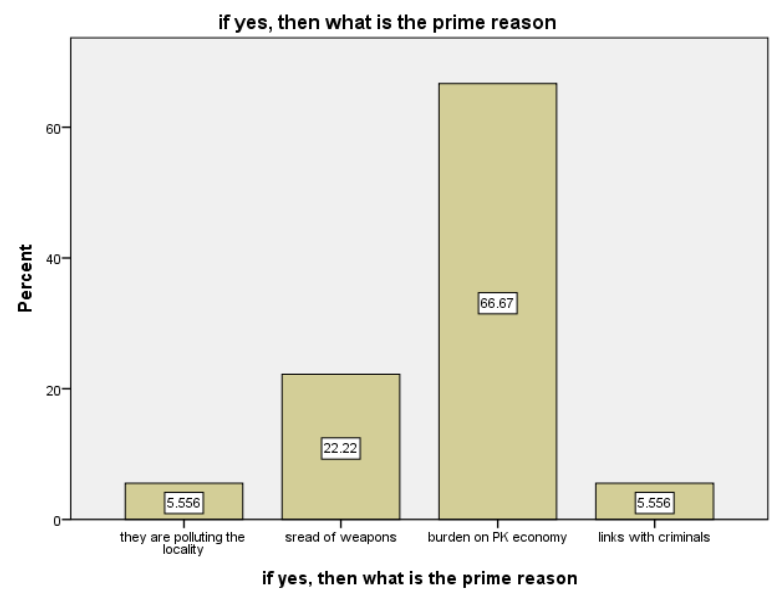

(fig.xvii) 


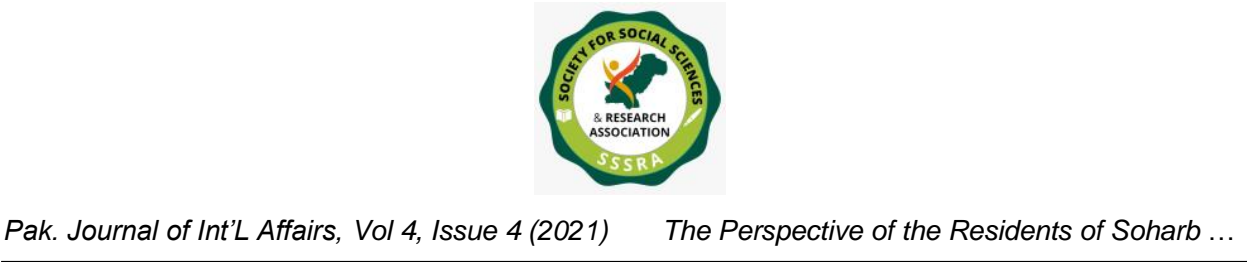

The above graph shows that $66.67 \%$ respondent were of the opinion that Afghan respondents were a burden on the economy of Pakaistan,22.22\% blamed the Afghan refugees for the spread of weapons, while $5.556 \%$ were of the opinion that the Afghan refugees were responsible for polluting the environment and having links with the criminals.

\section{DISCUSSION}

Migration of people from one country to another has become an international problem. As far as Pakistan is concerned it has been provided shelter not only to those refugees who came here after 1947, but to people of other countries. Out of those, the case of Afghanis is worth mentioning. A massive wave of Afghans came to take shelter in Pakistan after the Soviet invasion of 1979. After staying in the border areas of FATA, they spread across the country to find their bread and butter. Unfortunately there are proofs that the militants of Taliban and al-Qaida also came along with them, who became the root cause of terrorism in Pakistan, especially in Karachi. It has been reported that even Mullah Omer had been cited in Karachi. (Washington Times, 2009). The recent operation by the rangers have made possible to eliminate this factor to some extent. Afghanis with criminal record of any kind had been arrested and the area was made clear of anti-social elements. The vacant buildings in Machar Colony are a living proof of this event.

In order to have an overview the researcher got enthusiastic to know about this locality and to find as what outcome would be there in an area which once was declared as 'No Go Area'. The researcher also wished to know the real reason behind the migration of Afghan Refugees to this area that is Sohrab Goth. Besides hearing so much strange versions about Afghan refugees, the researcher wanted to find the reality and validity of the facts about these refugees. For this purpose the first step was to pilot testing of the questionnaire so the researcher stepped in the vicinity of Sohrab Goth. The first day was quite shocking as the researcher witnessed to observe the density and depth of the population of Pashto speaking people. It got very difficult to differentiate between an Afghan and a Pashtun. A taxi driver helped me in this matter and told me to contact the 'Nazim' of the nearest town called Haji Namatullah Town. The Nazim did not live there any more so the researcher started knocking at the doors. It was Sunday and last 'Ashra' of Ramadan. As expected, the female members were awake and were busy in their household work. They were not bothered as what the researcher wanted to know or why she was there. A young woman who was the only one to understand and converse in Urdu, warned the researcher to wait for her father, the eldest member of the family. It was after 1'oclock but there was no sign of any male member. AS soon as the elder person entered the room everyone went out he was accompanied by few young Pashtuns. The old man ( in his 80s) 


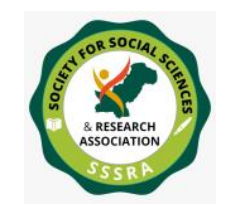

Pak. Journal of Int'L Affairs, Vol 4, Issue 4 (2021)

The Perspective of the Residents of Soharb ...

made it very clear that whatever he say would be note down and taken as the last words on behalf of the family. This trend was very unfamiliar for the researcher. The old man got very furious when some questions about the Afghan refugees were put to him. He spoke very ill about them. The researcher wanted to have the opinion of the much younger members of the family but they did not respond saying that please write whatever their father has said.

Keeping all this in mind, a questionnaire was prepared with some modification. A survey was conducted in two areas only because of time constraint, that is Haji Namatullah town and Macher Colony. The general feeling of the local residents of Sohrab Goth about the Afghans was positive (table4.4).Most of them very firmly said that though being Pashtuns they also like Afghan traditional food but definitely they would never adopt the eating habits of the Afghan refugees.(table4.6).Similarly the Pashtun residents of Sohrab Goth also denied this impression that as they had good relationship with the Afghans it does not mean that they would perhaps follow their traditional dressing or way of celebrating the different occasions.( table 4.6\&4.7)

Majority of the local residents had no problems with the Afghan refugees but they had kept a distance with them. Most of them were of the opinion that language barrier is there .Some showed their fear against the refugees and some complained that possession of weapons by the Afghans had forced them not to have any close relationship them.(fig4.8,4.9,4.10,4.11\&4.12).

When asked about the problems caused by the Afghan refugees in their areas, majority of the locals about $62.07 \%$ positively endorsed this that they had no problems what so ever with them. A group of locals were of the opinion that the Afghan refugees has been disturbing law and order situation of the area. Few showed their concern regarding hygienic condition of their area and few held them responsible for the spread of weapons in their community.(fig.4.13)

It was very noticeable that besides having complaint, the local residents were quite happy with the Afghan refugees.(fig.4.14).The reasons which poped up were that the majority of the locals said that the Afghans had started to earn their living by doing odd jobs which include collecting rubbish. They were even helping the local community in their work.(fig4.15). The local residents comprehensively said that its true that these Afghans were not a threat for these locals but they should go back from where they have come, as one should live there where the roots of them are.(fig 4.16) provided the situation in Afghanistan gets better. It was the opinion of the majority of the local residents that the Afghan refugees were trying to survive in a new country therefore, they were ready to do 


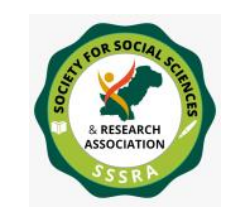

Pak. Journal of Int'L Affairs, Vol 4, Issue 4 (2021) The Perspective of the Residents of Soharb ...

anything to live. This would lead to the fear of some that they might have links with the Talibans. Therefore for the sake of the security of their areas and communities it would be a better idea that these Afghans should go back as soon as possible.

After conducting the survey and talking to a number of people, the researcher had reached to this conclusion that since 30-40 years Pakistan has been the host of these Afghans who fled Afghanistan to save their lives. Unfortunately many of them had settled here for good .Some of these refugees had started their business here in Karachi .Proofs of such can be gathered from some famous shopping malls of Defense and Clifton. They do not want to go back. There had been no proper system of their registration even. Very few had PoR cards. Recent operation of rangers in Karachi had created an unrest among these Afghans. Some of them had been arrested for being involved in different crimes. The vacant buildings in Macher Colony proved that the many criminals and members of Talibans crossed the border along with these Afghans.

This is food for thought for the Government of Pakistan as what further steps should be taken to stop this ongoing process of migration across the border of Durand Line. The stability and peace of Pakistan should be the priority of every Pakistani which requires a strict policy against the refugees, pouring in Pakistan from its North-Western borders

\section{Conclusion}

The phenomenon of migration is an ongoing process, taking place across the world. Pakistan being a developing country surrounded by so many problems from shortage of food to security threats has been a host to many refugees since its inception. The massive wave of refugees after 1979 has put Pakistan in an awkward situation. Afghanistan is our neighbor and Pakistan has always extended her hand in helping her neighbors. Unfortunately, in the case of Afghan refugees, Pakistan is facing a number of problems. It has been more than thirty years that Pakistan has become a new home for these refugees who have fled Afghanistan due to the ongoing war between the Afghan Government and Talibans and Al-Qaida. Many Talibans entered Pakistan along with these refugees through the porous border between Afghanistan and Pakistan. The Afghan refugees have spread across the country especially they have found shelter in the metropolitan city of the country, Karachi. The arrival of refugees is not only changing the demography of Karachi but it has become the root cause of an increasing number of terrorist activities in the city. Afghans had been coming to Karachi since 1970s as traders who use to come here to avoid extreme winters. 


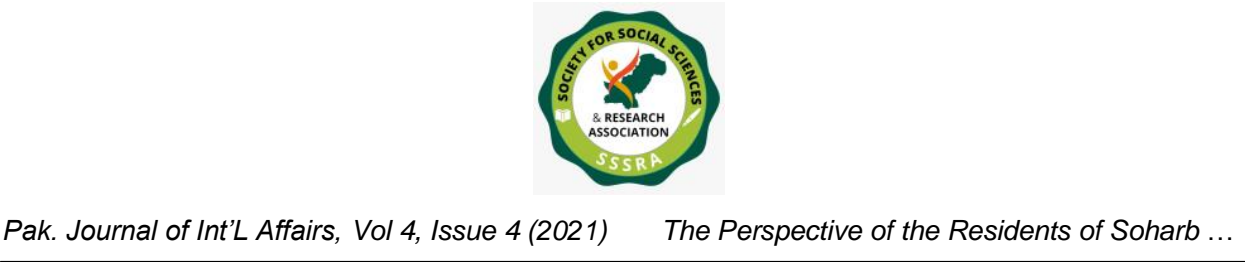

The great migration of Afghans from 1979 till 1990 has created a very fearful and disturbing impact on the city. The Afghans, due to familiarity in physical appearance and social set up got shelter in those localities of Karachi where there were Pashtuns. Slowly and gradually the Afghan refugees started settling in these areas. The wave of terrorism forced the city government to take vigorous action. The great massacre of 1986 made the local Pashtuns suffered. The Pashtuns had to move away from the main city and now they live in the outskirts of Gadap town. The Afghan refugee also moved along with them. The local Pashtuns have no problems with the Afghan refugees but they were of the opinion that these Afghans might become a problem for them as they had also started doing business. The local Pashtuns were worried that the Afghans were trying to take over their business as they had opened their own shops in different shopping centers of Karachi, especially Gulshan Iqbal, and Tariq road. This would result in the decline in their business.

The law and order situation of Karachi had also worsened after 1990. Some of the local Pashtuns do not blame Afghan refugees for this but they were of the opinion that because of them the local police had been creating problems for all. This was the reason as why the local Pashtuns thought that the Afghan should go back. Thus, it is up to the government as what kind of action it would take to maintain law and order situation of the city especially as far as the case of Afghan refugees is concerned.

\section{Limitations}

There were a number of problems faced by the researcher during the survey for this research. The most important was education. The graph showed that about $70 \%$ of the local residents of Sohrab Goth were non-matric. This proved a big hindrance in making them understand about the survey. Then the females of Sohrab Goth were typical uneducated housewives who were neither interested in the survey nor they wanted to participate. This was the reason that the number of female respondents was kept two only. The other problem was that in some Pashtun families the youngsters were not allowed to speak up. It was out of respect for them but became a problem for the researcher. Thirdly, the researcher wanted to take some photographs but the locals did not allow this. A young boy was deputed with the researcher for this purpose.

\section{Recommendations}

Following recommendations have been made after this research.

Government of Pakistan should speed up the process of repatriation of Afghan Refugees. 
Census should be held immediately to have the exact number of Afghan refugees in Pakistan.

$>$ The government should allow the Afghans, born after 1990 to have a dual nationality that is of Pakistan and of Afghanistan in order to give a peace of mind to the upcoming generation of Afghan refugees.

$>$ The Sind Government should confined the Afghan refugees to one district only in order to observe and have a check and balance over the activities of these refugees. 
The Perspective of the Residents of Soharb ...

\section{References}

Afghans in Karachi.Migration,Settlement\&Social Network. (2005, March). UNCHR for AREU.

Bengaliwala, K. (2011, november 1). Retrieved August 22, 2016, from www.the news.com.

Centlivres-Demont, P. C. (1988). The Afghan Refugee in Pakistan: Ambigious Identity. Journal of Refugee Studies, 1(2).

Freeman, G. (n.d.). Political Science and ComparativeImmigration Politics. Retrieved July 24, 2016, from www.tullane.edu/ dnelson/PEMigConf/Freeman.pdf.

Gufran, N. (n.d.). Afghan Refugees in Pakistan. Current situation and Future Scenario. Policy Perspective, 3(2).

Hasan, A. (1987, February). The Sohrab Goth massacre.

Hollifield, J. (1992). Refugees,Markets ans States: The political economy Postwar Europe. Cambridge,MA: Harvard University Press.

Khan, F. S. (2016, February 1). Afghan Refugees.

Nasreen, G. (n.d.). Afghan Refugees in Pakistan. Current Situation and Future Scenarion. Policy Perspectives, 3(2).

Stephen Castle, H. H. (1993). The Age of Migration. IOM iInternational Organization for Migration.

The Great Migration: How Modern Humans Spread across the World. (2009, february 11). Retrieved july 27, 2016, from Independent.co.uk/news.

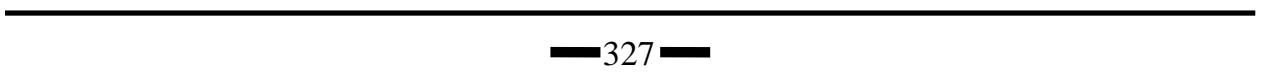

